\begin{tabular}{|c|c|}
\hline Title & A Facile Method to Fabricate A nisotropic Hydrogels with Perfectly A ligned Hierarchical Fibrous Structures \\
\hline Author(s) & $\begin{array}{l}\text { Mredha, Md. Tariful Islam; Guo, Y un Zhou; Nonoyama, Takayuki; Nakajima, Tasuku; Kurokawa, Takayuki; Gong, } \\
\text { Jian Ping }\end{array}$ \\
\hline Citation & $\begin{array}{l}\text { A dvanced Materials, 30(9), } 1704937 \\
\text { https://doi.org/10.1002/adma.201704937 }\end{array}$ \\
\hline Issue Date & $2018-03-01$ \\
\hline Doc URL & http:/hdl.handle.net/2115/73741 \\
\hline Rights & $\begin{array}{l}\text { This is the peer reviewed version of the following article: https://onlinelibrary .wiley .com/Journal } / 15214095 \text { which has } \\
\text { been published in final form at https://doi .org/10.1002/adma.201704937. This article may be used for non-commercial } \\
\text { purposes in accordance with W iley Terms and Conditions for Self-A rchiving. }\end{array}$ \\
\hline Type & article (author version) \\
\hline File Information & A uthor's manuscript_HU Library.pdf \\
\hline
\end{tabular}

Instructions for use 


\section{Advanced Materials}

\section{A Facile Method to Fabricate Anisotropic Hydrogels with Perfectly Aligned Hierarchical Fibrous Structures \\ --Manuscript Draft--}

\begin{tabular}{|c|c|}
\hline Manuscript Number: & adma.201704937R1 \\
\hline Full Title: & $\begin{array}{l}\text { A Facile Method to Fabricate Anisotropic Hydrogels with Perfectly Aligned Hierarchical } \\
\text { Fibrous Structures }\end{array}$ \\
\hline Article Type: & Communication \\
\hline \multicolumn{2}{|l|}{ Section/Category: } \\
\hline Keywords: & Anisotropy; hierarchy; fiber; drying in confined conditions; hydrogel \\
\hline Corresponding Author: & $\begin{array}{l}\text { Jian Ping Gong, Prof. } \\
\text { Hokkaido University } \\
\text { Sapporo, JAPAN }\end{array}$ \\
\hline \multicolumn{2}{|l|}{ Additional Information: } \\
\hline Question & Response \\
\hline $\begin{array}{l}\text { Please submit a plain text version of your } \\
\text { cover letter here. } \\
\text { If you are submitting a revision of your } \\
\text { manuscript, please do not overwrite your } \\
\text { original cover letter. There is an } \\
\text { opportunity for you to provide your } \\
\text { responses to the reviewers later; please } \\
\text { do not add them here. }\end{array}$ & $\begin{array}{l}\text { August } 29,2017 \\
\text { Peter Gregory } \\
\text { Editor-in-Chief } \\
\text { Advanced Materials } \\
\text { Dear Professor Gregory, } \\
\text { I submit herewith a manuscript entitled 'A Facile Method to Fabricate Anisotropic } \\
\text { Hydrogels with Perfectly Aligned Hierarchical Fibrous Structures', by Md. Tariful Islam } \\
\text { Mredha, Takayuki Nonoyama, Tasuku Nakajima, Yun Zhou Guo, Takayuki Kurokawa } \\
\text { and me for publication as a communication in the Advanced Materials. } \\
\text { In this research work, we introduced a very facile novel method (drying a low density } \\
\text { physical hydrogel in confined condition), by which we have been able to make perfectly } \\
\text { aligned fibrous hydrogel with biomimetic hierarchical structures. By this method, we } \\
\text { can induce sufficiently high internal force to align the polymer chains and } \\
\text { simultaneously, can achieve fiber forming high concentration of polymers through } \\
\text { drying process. We can control the bottom-up growth of polymers from the nano-to- } \\
\text { submicron-to-micro scales in the macro-sized hydrogel. The method is useful for } \\
\text { relatively rigid polymers such as alginate, cellulose etc. The mechanical and structural } \\
\text { properties are comparable with natural ligaments. We can tune structure, alignment } \\
\text { and toughness of the material within wide window by controlling its internal } \\
\text { supramolecular interactions. The study would be a breakthrough in materials science } \\
\text { for designing hydrogels with highly ordered hierarchical structures, which may find } \\
\text { various bio-applications in future. } \\
\text { This work is original. Any content of this manuscript in any form has not been } \\
\text { published, not under consideration for publication elsewhere, and its submission for } \\
\text { publication has been approved by all of the authors. } \\
\text { May I request you to take necessary steps for publishing this article in Advanced } \\
\text { Materials. } \\
\text { I look forward to hearing from you with the hope of its rapid publication. } \\
\text { Sincerely, } \\
\text { Jian Ping Gong Distinguished } \\
\text { Wet Matter } \\
\text { Faculty of Advanced Life Science, Hokkaido University } \\
\text { \& Director }\end{array}$ \\
\hline
\end{tabular}


Global Station for Soft Matter, GI-CoRE, Hokkaido University

North 21 West 11, Kita-ku, Sapporo 001-0021, Japan

TEL \& FAX: +81-(0)11-706-9011

E-mail: gong@sci.hokudai.ac.jp

Do you or any of your co-authors have a conflict of interest to declare?

\section{Corresponding Author Secondary} Information:

\section{Corresponding Author's Institution:}

Hokkaido University

Corresponding Author's Secondary Institution:

\section{First Author:}

First Author Secondary Information:

Order of Authors:

Order of Authors:

Order of Authors Secondary Information:

Abstract:

Hokkaido University

No. The authors declare no conflict of interest.

rar.

Md. Tariful Islam Mredha, PhD

Md. Tariful Islam Mredha, PhD

\author{
Yun Zhou Guo \\ Takayuki Nonoyama, PhD \\ Tasuku Nakajima, PhD \\ Takayuki Kurokawa, Prof. \\ Jian Ping Gong, Prof.
}

Abstract:


DOI: $10.1002 /($ please add manuscript number)

\section{A Facile Method to Fabricate Anisotropic Hydrogels with Perfectly Aligned Hierarchical Fibrous Structures}

Md. Tariful Islam Mredha ${ }^{1}$, Yun Zhou Guo ${ }^{2}$, Takayuki Nonoyama ${ }^{1,3}$, Tasuku Nakajima ${ }^{1,3}$, Takayuki Kurokawa ${ }^{1,3}$, and Jian Ping Gong ${ }^{1,3 *}$

Dr. Md. T. I. Mredha, Dr. T. Nonoyama, Dr. T. Nakajima, Prof. T. Kurokawa, Prof. J. P. Gong

${ }^{1}$ Faculty of Advanced Life Science, Hokkaido University, Sapporo 001-0021, Japan

Y. Z. Guo

${ }^{2}$ Graduate School of Life Science, Hokkaido University, Sapporo 001-0021, Japan

Dr. T. Nonoyama, Dr. T. Nakajima, Prof. T. Kurokawa, Prof. J. P. Gong

${ }^{3}$ Global Station for Soft Matter, Global Institution for Collaborative Research and Education (GI-CoRE), Hokkaido University, Sapporo 001-0021, Japan

E-mail: gong@sci.hokudai.ac.jp

Keywords: Anisotropy, hierarchy, fiber, drying in confined conditions, hydrogel

Many methods have been developed to make polymer fibers in dry or hydrogel form including wet/melt spinning, electrospinning, and microfluidic techniques, where polymer solutions or melts are drawn as fibers with diameters on the order of micrometers to submicrometers. ${ }^{[1-8]}$ Constructing an anisotropic bulk hydrogel containing hierarchical fibrous architecture is still a challenge. We aim to develop a facile method to fabricate anisotropic hydrogels with hierarchical fibrous architectures. A material with such a structure is expected to exhibit mechanical properties similar to those of load bearing natural tissues such as ligaments and tendons. We have to learn from nature to achieve this. During tissue morphogenesis, biopolymers such as collagen are secreted from cells and assembled into fibrils, which can arrange laterally to form self-templated dense structures with hierarchy from the nanoscopic to the macroscopic length scales..$^{[9,10]}$ It has been shown that both complex mechanical signals from the cell and dynamic supramolecular interactions among biopolymers play important roles in the creation of self-templated hierarchical 


\section{WILEY-VCH}

architectures. $^{[11,12]}$ The rigid and rich interaction sites such as charges and H-bonds of biopolymers are indispensable for structure formation. A rigid chain is more susceptible than a flexible chain to orient in response to a mechanical signal. ${ }^{[13]}$ Lateral interactions between polymer chains stabilizes the oriented structure. Although each physical interaction is very weak, the supramolecular interaction through the summation of directionally controlled hierarchical architecture could be very strong. ${ }^{[12]}$ Inspired by nature, we propose a facile method by which we can induce spontaneous mechanical signals and tune supramolecular interactions among polymers to create hydrogels with highly aligned self-templated hierarchal structures similar to those of the collagen fibril structure in tendons and ligaments. This type of structure, to the author's knowledge, is observed for the first time. This type of material with hierarchal structure has high potential in biomedical applications such as artificial tendons and ligaments.

Our facile method includes drying a piece of diluted physical hydrogel consisting of semirigid/rigid polymers in air at a confining geometry, as shown in Figure 1(I). This drying in confined condition method is abbreviated DCC. During drying, the gel shrinks due to the evaporation of water (Figure 1(II)). As its two ends are fixed, the width and thickness of the hydrogel will shrink, but not the length. Therefore, the gel experiences tensile stress in the length direction during drying, causing orientation of the polymer chains along the length direction. When dried, the polymer concentration increases and above a critical concentration the polymers form nanofibrils through supramolecular interactions (Figure 1(II)). Further drying induces aggregation of nanofibrils to form thicker fibers. The process is repeated to form the hierarchical fibrous structure of the gel (Figure 1(III)). The re-swollen gel maintains the same structure due to the formation of stable supramolecular interactions (Figure 1(IV)). 


\section{WILEY-VCH}

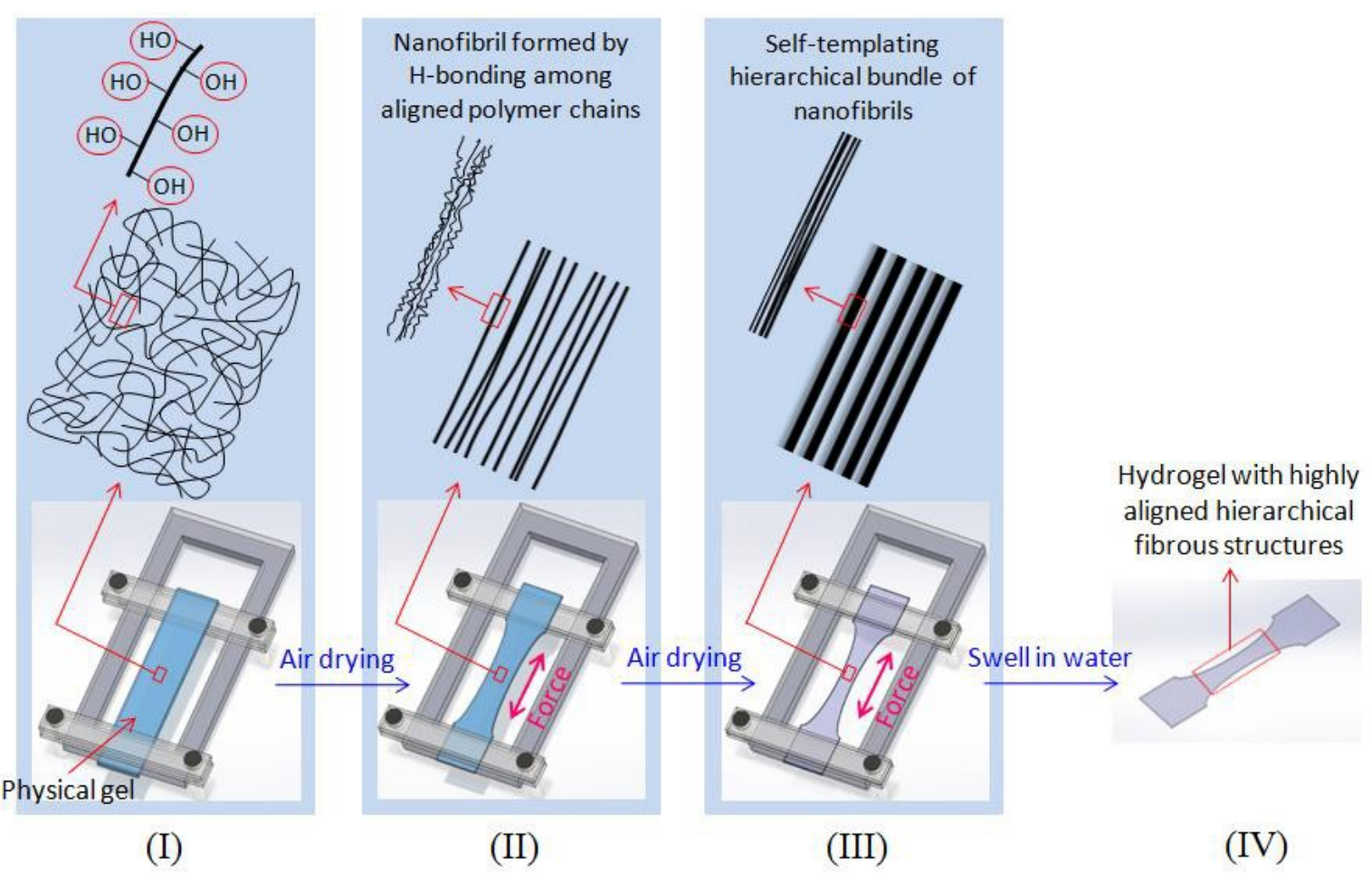

Figure 1. Design strategy. Schematic illustrations of DCC (drying in confined condition) method for creating perfectly aligned fibrous hydrogels with hierarchical superstructures. A rectangular piece of physical hydrogel (having fiber-forming $\mathrm{H}$-bonding sites) is clamped to a sample holder at its two long ends (I). The gel is left to dry in air. Due to volume contraction during drying process, the gel's width and thickness shrink. As the shrinking in the length direction is restricted by the sample holder, the gel experiences tension along the length direction, which aligns the polymer chains in the length direction. When polymer density reaches the fiber forming concentration by drying, thin fibrils are formed along the tensile direction through $\mathrm{H}$-bond formation (II). Further drying induces aggregation of nanofibrils to form thick fibers; this process is repeated to form the hierarchical fibrous structure of the gel (III). The re-swollen gel maintains the same structure due to the formation of stable $\mathrm{H}$-bonds (IV).

Different rigid/semi-rigid linear polysaccharides such as alginate, cellulose, and chitin are critical to the morphogenesis and functionality of various hierarchically ordered natural materials. ${ }^{[1,14,15]}$ Alginate — a biodegradable negatively charged biopolymer originating from seaweed - bears structural similarity to glycosaminoglycan, one of the major components of the extracellular matrix. ${ }^{[1]}$ Alginate forms a physical hydrogel in the presence of divalent $\mathrm{Ca}^{2+}$ ions through ionic cross-linking. ${ }^{[16]}$ We chose Ca-alginate gel as one of the model physical gels to evaluate the potency of the DCC method. The ionic interactions can be sacrificed easily during the DCC process, which allows the polymers to align along the stress direction. 


\section{WILEY-VCH}

Being a polysaccharide, alginate has many hydrogen bonding sites, which could serve as the driving force for fiber formation.

To apply DCC method to an alginate system, Ca-alginate gel with diluted polymer concentration was prepared by diffusion of $0.5 \mathrm{M} \mathrm{Ca}^{2+}$ into $4 \mathrm{wt} \%$ aq. Na-alginate solution (Supporting Information, Figure S1). The gel shrunk slightly during gelation. The Caalginate gel $-1.5 \mathrm{~mm}$ thick and containing $\sim 95 \mathrm{wt} \%$ water-was cut to rectangular shape of size $10 \mathrm{~mm} \times 50 \mathrm{~mm}$, and its two long ends were clamped using a home-made holder, as shown in Figure 1(I). After clamping, the effective length (the part that was exposed to air) of the sample was $30 \mathrm{~mm}$. The gel was allowed to dry in air (temperature: $25^{\circ} \mathrm{C}$, humidity: $40-$ $60 \%$ ). After complete air drying, the gel was re-swollen in water until it reached equilibrium. The final hydrogel prepared was termed DCC-alginate gel. The water contents of re-swollen DCC-alginate gels were in the range $56-58 \mathrm{wt} \%$ (Table 1). This was very close to that of natural ligaments $(60-70 \mathrm{wt} \%) .{ }^{[17]}$ The air-dried alginate showed less rehydration ability than the initial state, indicating the formation of stable hydrogen bonding among polymer chains by drying. As shown by scanning electron microscopic (SEM) observations, though the starting Ca-alginate gel had no oriented structure (Figure S1) a thick fibrous structure aligned along axial direction was observed in the DCC-alginate gel (Figure 2(a-i)). Each microfiber was a bundle of several sub-micrometer-sized fibers (Figure 2(a-ii, iii)). The sub-micrometersized fibers contained several nanometer-sized thin fibers (Figure 2(a-iv, v)). Thus, at least three scales of hierarchical structure were identified. SEM image of the axial cross-section of the DCC-alginate gel revealed a similar highly aligned hierarchical structure (Figure 2(a-vi, vii)). We also prepared gels by applying 50\% pre-stretching on the physical alginate gel while performing DCC. This gel—termed 50\%DCC-alginate gel—also showed three scales of hierarchical structure (Figure 2 (b-i, ii)). The angle distribution of the microfibers of the $50 \%$ DCC-alginate gel was slightly sharper than that of the DCC-alginate gel (Figure 2(c)). 


\section{WILEY-VCH}

The diameter distribution of the microfibers was narrower and the average diameter smaller

(Figure 2(d)). Birefringence of the 50\%DCC-alginate gel—calculated from polarizing optical microscopic (POM) observations - was higher than that of the DCC-alginate gel (Figure S2). These results indicated that the microfibers were more aligned and smaller in size in the prestretched gel. The results showed that we could tune the degree of alignment and superstructure size by varying the degree of pre-stretching during DCC. We could not prestretch more than $50 \%$ for alginate gel as the gel broke after some time during the DCC process. Microfibers of both DCC-alginate and 50\%DCC-alginate gels could be considered perfectly aligned as the maximum deviation of fibers with respect to the axial direction was only $2^{\circ}$ (Figure 2(c)). To the best of the authors' knowledge, this was the first success in obtaining alginate hydrogel with hierarchical fibrous structure and perfect alignment of fibers. We investigated the structure of a gel prepared by normal drying (ND) (without confinement) and re-swelling. The sample thus prepared was termed ND-alginate. The water content of ND-alginate gel was similar to that of DCC-alginate gel (Table 1). No oriented microstructure was observed in the ND-alginate gel (Figure 2(e-i, ii)). 

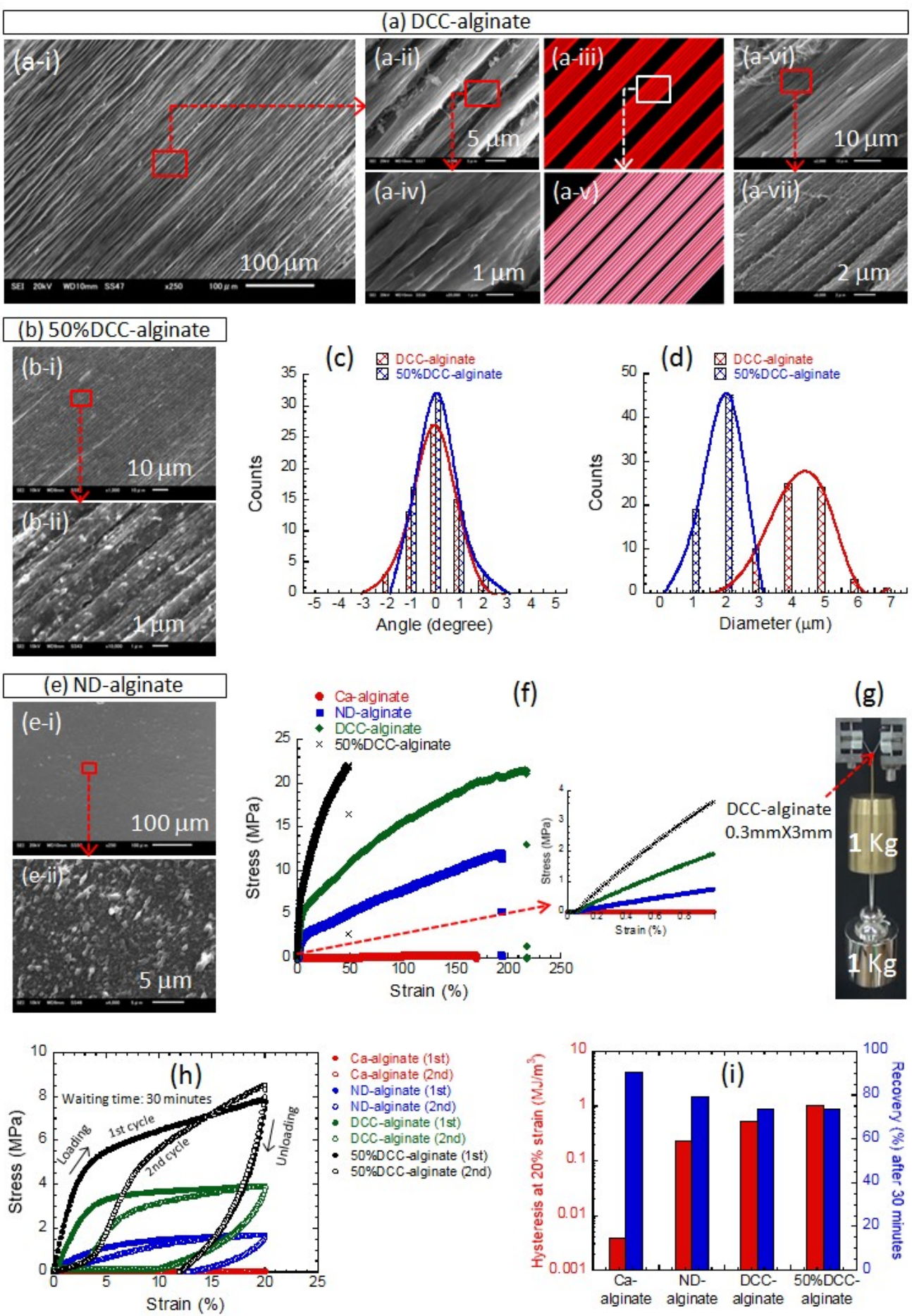

(f)

(g)
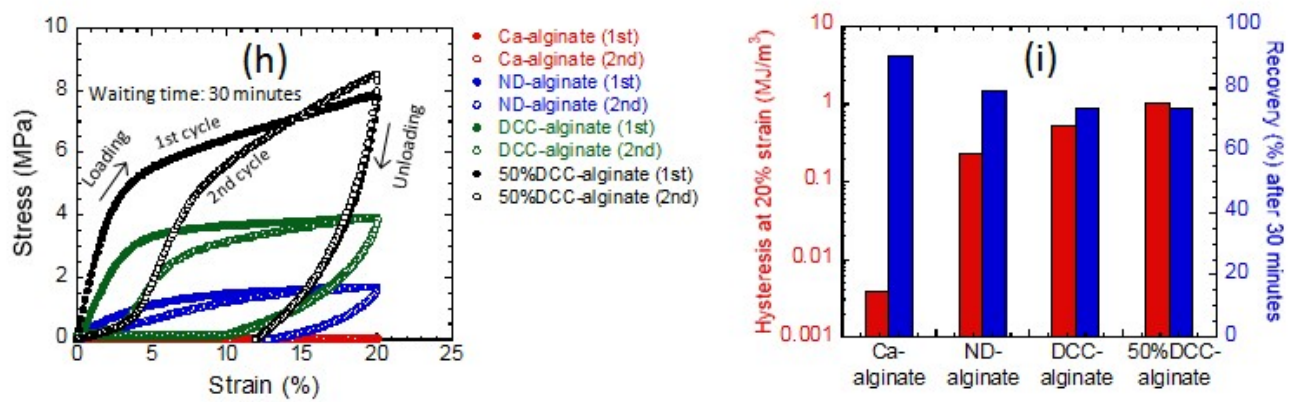

Figure 2. (a: i-vii) Structural analysis of DCC-alginate gel by SEM observation. Uniaxially aligned microfibers could be seen on the surface of DCC-alginate gel (a-i). Each microfiber was a bundle of several sub-micrometer-sized fibers (a-ii), as illustrated in (a-iii). Each of those sub-micrometer fibers was further composed of a nanofibrillar array (a-iv), which is illustrated in (a-v). SEM images of the axial cross-section of DCC-alginate gel indicated that fibrillar arrangements were retained in the bulk gel (a-vi, vii). (b-i, ii) SEM images of $50 \%$ DCC-alginate gel, where similar hierarchical structure was observed. (c, d) The distribution of microfiber angle with respect to the axial direction and the microfiber diameters of DCC-alginate and 50\%DCC-alginate gels derived from (a-i) and (b-i), respectively, using image processing software. (e-i, ii) SEM images of ND-alginate gel, which 


\section{WILEY-VCH}

suggested that no fibrillar structure was formed. (f) Tensile stress-strain curves of alginate hydrogels. Inset shows magnification of the low-strain region of the stress-strain curve. (g) An image demonstrating the high load bearing capacity of the DCC-alginate hydrogel. (h) Cyclic loading-unloading curves of alginate hydrogels. The waiting time between the first and the second cycle was $30 \mathrm{~min}$. (i) Hysteresis area and recovery-estimated from the ratio of the second hysteresis area to the first hysteresis area. Tensile tests were performed at strain rate of $10 \mathrm{~mm} / \mathrm{min}$ in air at $25^{\circ} \mathrm{C}$.

The mechanical performances of gels prepared by the DCC method were better than those of the ND-alginate and initial Ca-alginate gels (Figure 2(f)). Figure 2(g) shows that a tiny cord of DCC-alginate gel (cross-section area: $\sim 0.3 \mathrm{~mm} \times 3 \mathrm{~mm}$ ) was able to bear a load of $2 \mathrm{~kg}$ without breaking. Tensile experiments indicated that the Young's modulus $(E)$, fracture stress $\left(\sigma_{\mathrm{f}}\right)$, and fracture strain $\left(\varepsilon_{\mathrm{f}}\right)$ of the DCC-alginate gel increased significantly relative to the NDalginate gel (Figure 2f). The toughness of DCC-alginate gel—characterized by work of extension $(W)$-increased significantly (Table 1). Modulus of the 50\%DCC-alginate gel increased further while the fracture stress maintained the similar value; fracture strain decreased significantly relative to that of the DCC-alginate gel (Figure 2f). The aligned superstructure in DCC-alginate gel led to increase in modulus and fracture stress due to the formation of fiber structure. The increase in fracture strain of the DCC-alginate gel was unique as the strength and extensibility usually change in opposite directions. Even though we observed almost perfectly aligned microfibers, the nanofibrils were still not fully stretched. When stretched, the nanofibrils might break bonding with other nanofibrils to show high stretchability. Due to high degree of alignment in the 50\%DCC-alginate gel, the nanofibril could not stretch more, leading to fracture at low strain.

Cyclic loading-unloading test was performed to find out if an energy dissipation mechanism was involved in the deformation of alginate gels. Mechanical hysteresis was observed with all the alginate hydrogels (Figure 2(h, i)), which indicated the presence of sacrificial bonds that broke during deformation. At the same $20 \%$ strain, the hysteresis area increased with degree 


\section{WILEY-VCH}

of fiber orientation. The DCC-alginate and 50\%DCC-alginate showed hysteresis areas as high as 0.5 and $1 \mathrm{MJ} / \mathrm{m}^{3}$, respectively. After $30 \mathrm{~min}$ of waiting, about $75 \%$ of these hysteresis areas were recovered (Figure 2(i)). This indicated that the sacrificial bonds were almost reversible. Both ionic and hydrogen bonds serve as reversible sacrificial bonds to toughen the hydrogels.

Table 1. Mechanical properties and water contents of hydrogels prepared under different conditions. All the properties were measured after re-swelling in water. Data are presented as average value with standard deviation from three measurements. Data are compared with human knee ligaments.

\begin{tabular}{|c|c|c|c|c|c|c|}
\hline Hydrogel name & Sample description & $\begin{array}{l}\text { Young's } \\
\text { modulus, } E \\
\text { (MPa) }\end{array}$ & $\begin{array}{l}\text { Fracture } \\
\text { stress, } \sigma_{\mathrm{f}} \\
(\mathrm{MPa})\end{array}$ & $\begin{array}{c}\text { Fracture } \\
\text { strain, } \varepsilon_{\mathrm{f}}(\%)\end{array}$ & $\begin{array}{l}\text { Work of } \\
\text { extension, } \\
W\left(\mathrm{MJ} / \mathrm{m}^{3}\right)\end{array}$ & $\begin{array}{l}\text { Water } \\
(\mathrm{wt} \%)\end{array}$ \\
\hline Ca-alginate & Initial swollen sample & $0.39 \pm 0.05$ & $0.32 \pm 0.03$ & $145.9 \pm 23.3$ & $0.24 \pm 0.05$ & 95 \\
\hline ND-alginate & Free dried & $64.02 \pm 14.35$ & $10.26 \pm 1.76$ & $178.4 \pm 14.7$ & $11.78 \pm 2.79$ & 56 \\
\hline DCC-alginate & DCC without pre-stretching ${ }^{\# 1}$ & $203.3 \pm 14.33$ & $22.43 \pm 0.93$ & $201.4 \pm 15.9$ & $30.88 \pm 1.97$ & 57 \\
\hline $50 \% \mathrm{DCC}$-alginate & DCC at $50 \%$ pre-stretching & $367.35 \pm 54.49$ & $19.80 \pm 2.24$ & $51.1 \pm 2.5$ & $7.04 \pm 0.45$ & 56 \\
\hline p-Cellulose & Initial swollen sample & $2.49 \pm 0.21$ & $1.58 \pm 0.09$ & $204.8 \pm 11.0$ & $1.48 \pm 0.14$ & 88 \\
\hline ND-cellulose & Free dried & $19.20 \pm 0.89$ & $12.62 \pm 0.40$ & $407.7 \pm 34.9$ & $20.62 \pm 2.18$ & 59 \\
\hline DCC-cellulose & DCC without pre-stretching & $59.0 \pm 6.57$ & $25.80 \pm 1.33$ & $267.3 \pm 1.3$ & $38.03 \pm 2.83$ & 58 \\
\hline $50 \%$ DCC-cellulose & DCC at $50 \%$ pre-stretching & $150.67 \pm 11.79$ & $39.33 \pm 7.31$ & $102.2 \pm 9.0$ & $32.04 \pm 1.75$ & 58 \\
\hline $100 \%$ DCC-cellulose & DCC at $100 \%$ pre-stretching & $342.44 \pm 31.14$ & $53.55 \pm 0.53$ & $34.7 \pm 6.4$ & $16.44 \pm 0.99$ & 58 \\
\hline Knee ligaments ${ }^{\# 2}$ & - & $65-447$ & $13-46$ & $11-44$ & - & $60-70$ \\
\hline
\end{tabular}

${ }^{\# 1}$ DCC: drying in confined condition.

${ }^{\# 2}$ Human knee ligament data from medial collateral ligament (MCL), anterior cruciate ligament (ACL), and posterior cruciate ligament (PCL) are shown. ${ }^{[17,18]}$

We further observed the progress of hierarchical fibrous structure formation of alginate gel in situ during DCC by POM observation (Figure 3(a-c)). Orientation strength (retardation value) increased linearly with drying time during the DCC process and reached equilibrium after a prolonged time of $300 \mathrm{~min}$ (Figure 3(a, c)). The air-dried gel showed slight reswelling in water causing slight decrease in orientation strength, and then became stable (Figure 3(b, c)). These results indicated that the aligned microstructure of the gel was formed slowly as the DCC process progressed. The final structure remained stable upon re-swelling. The air-dried gel swelled in the width and thickness directions with dimension ratios of 1.32 


\section{WILEY-VCH}

and 1.26, respectively. The gel did not swell in the length dimension. The swelling only

(a) DCC process

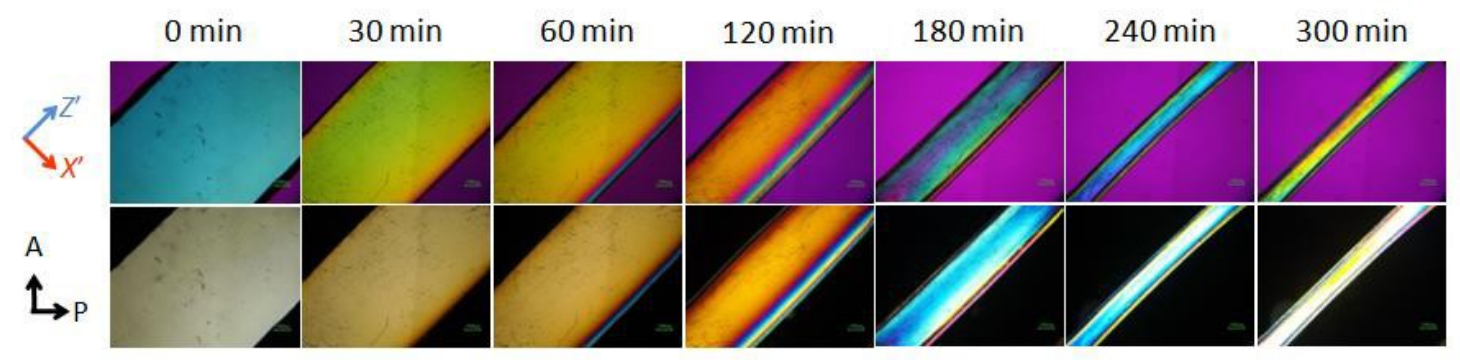

$\stackrel{5 \mathrm{~mm}}{\longleftrightarrow} \quad$ (b) Re-swelling in water
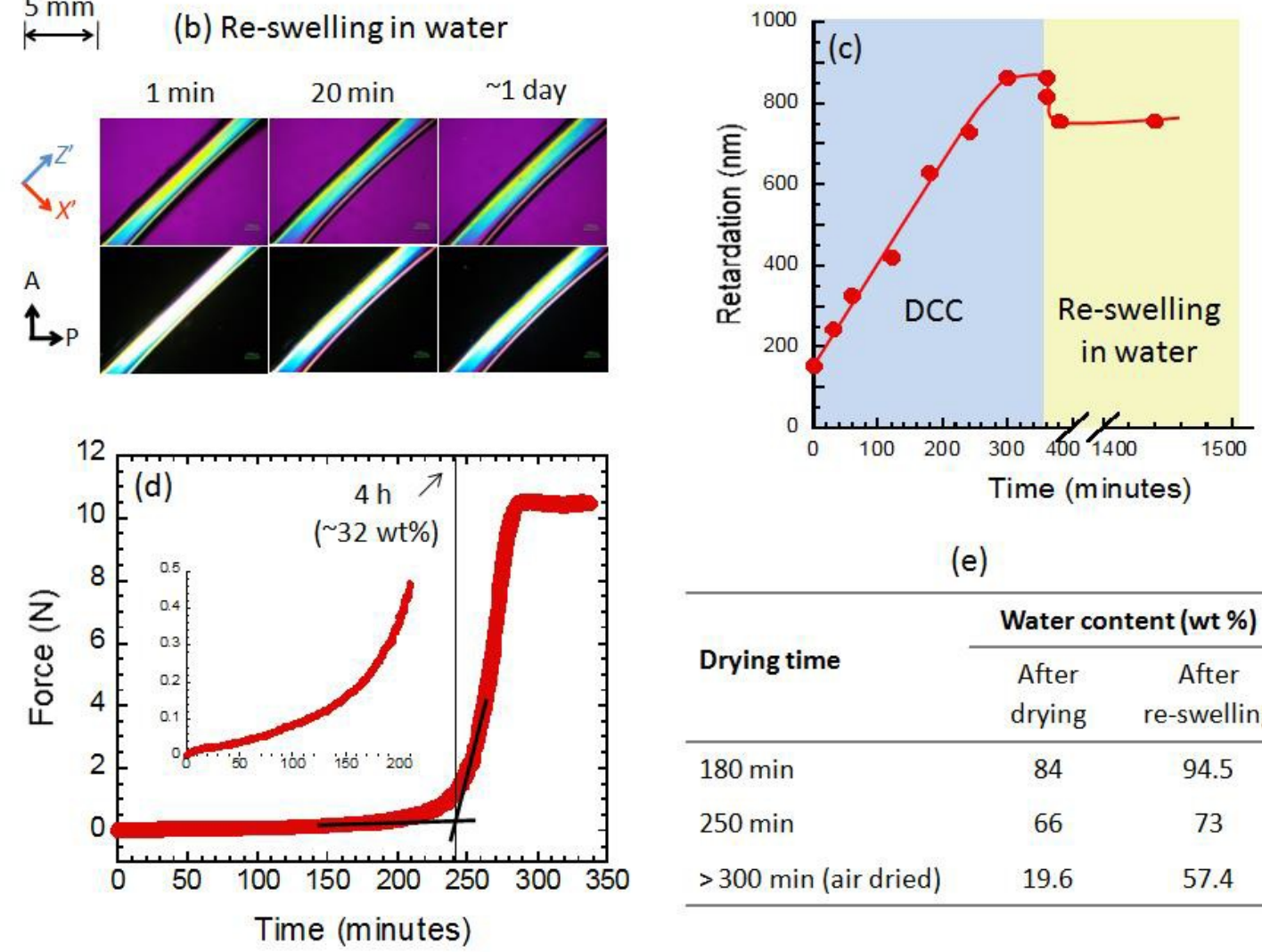

(e)

\begin{tabular}{lcc}
\hline \multirow{2}{*}{ Drying time } & \multicolumn{2}{c}{ Water content (wt \%) } \\
\cline { 2 - 3 } & $\begin{array}{c}\text { After } \\
\text { drying }\end{array}$ & $\begin{array}{c}\text { After } \\
\text { re-swelling }\end{array}$ \\
\hline $180 \mathrm{~min}$ & 84 & 94.5 \\
$250 \mathrm{~min}$ & 66 & 73 \\
$>300 \mathrm{~min}$ (air dried) & 19.6 & 57.4 \\
\hline
\end{tabular}

(f)
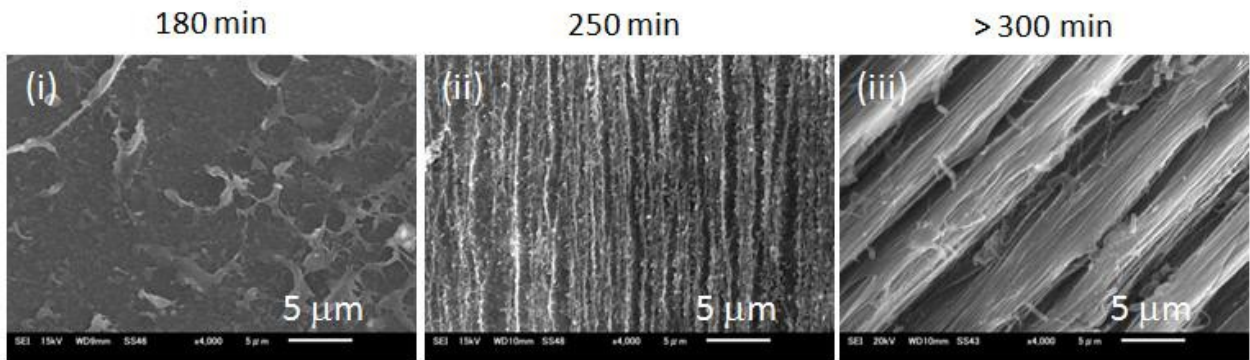

Figure 3. In situ observation of hierarchical fibrous structure formation of Ca-alginate hydrogel. (a) Polarizing optical microscopic (POM) images of $\mathrm{Ca}$-alginate hydrogel during 


\section{WILEY-VCH}

DCC in the presence (upper row) and absence (lower row) of $530 \mathrm{~nm}$ tint plate. Sample at initial state: water content $=95 \mathrm{wt} \%$, thickness $=1.5 \mathrm{~mm}$, width $=10 \mathrm{~mm}$, length between two confined ends $=30 \mathrm{~mm}$. (b) POM images during reswelling of air-dried gel. All POM images are shown at the same scale. A: analyzer, P: polarizer. $X^{\prime}$ and $Z$ ': fast and slow axes of the tint plate, respectively. (c) The variation in orientation degree (in terms of retardation value) during DCC and reswelling. (d) Time profile of contractive force developed in the alginate hydrogel along the axial direction during DCC. Inset shows magnification of the initial part of the time profile. (e) Water content of the alginate hydrogel before and after reswelling with three different drying times (180 min, $250 \mathrm{~min}$, and over $300 \mathrm{~min}$ ) in the DCC process. (f) Corresponding SEM images of these three samples after being re-swollen in water.

To clarify the mechanism of oriented-structure formation, we measured the axial contraction force of the gel generated during DCC process using a tensile tester. As shown in Figure 3(d), the contraction force increased gradually with time at the beginning of the drying process. It increased abruptly at $\sim 240$ min when the polymer content increased to $\sim 32 \mathrm{wt} \%$. On further drying, the contraction force saturated to a constant value of $10.55 \mathrm{~N}$ when the water content of the gel decreased to an equilibrated value $(19.6 \mathrm{wt} \%)$. From the dimensions of the dried sample (size: $2.3 \mathrm{~mm} \times 0.26 \mathrm{~mm} \times 30 \mathrm{~mm}$ ), a contraction stress of $\sim 17.6 \mathrm{MPa}$ was estimated. We speculated that before the transition point ( $\sim 240 \mathrm{~min})$, interactions between polymer chains were weak or negligible and the contraction force was related to the rubber elasticity of the polymer chains. At the transition point $(\sim 240 \mathrm{~min}$, where the contraction force abruptly increased), polymers aggregated to form a stable hierarchical fibrous structure. To justify this speculation, we prepared two DCC-alginate hydrogels by performing the DCC process for $180 \mathrm{~min}$ (before the transition point) and $250 \mathrm{~min}$ (after the transition point). The gels were re-swelled in water and their structures observed by SEM. The gel prepared by the DCC process for 180 min returned to its original shape and water content (Figure 3(e)) after reswelling and no oriented structure was identified (Figure 3(f-i)). The water content of DCCalginate gel prepared at 250 min did not change much after re-swelling (Figure 3(e)) and the gel possessed aligned nanofibril structures (Figure 3(f-ii)). The re-swollen gel of the sample with complete air-drying (time $>300 \mathrm{~min}$ ) contained thick micrometer-sized fibers consisting of nanofibrils (Figure 3(f-iii)). These results indicated that the abrupt transition in the force vs. 


\section{WILEY-VCH}

time profile corresponded to the starting point for the formation of a hierarchical fibrous structure.

The above results showed that DCC drying produced different structures from normal isotropic drying. In the DCC method, the gel was contracted along the width and thickness directions. Contraction in length direction was prevented by clamping (Table S1). Due to anisotropic contraction, the gel was effectively stretched along the length direction as drying progressed, as shown by the large contraction force generated spontaneously in the axial direction during DCC (Figure 3(d)). Due to this force, the polymer was progressively oriented along the axis (Figure 3(a, c)). When the polymer density reached its fibril forming concentration ( $\sim 32 \mathrm{wt} \%$, the inflection point of the force vs. time curve), the aligned polymer chains became sufficiently close to each other to form stable nanofibrils. The nanofibrils continued aggregating to form submicroscale fibers and the submicroscale fibers further aggregated to form micrometer-scale fibers within the bulk hydrogel. The rigid nature of the polysaccharide made the supramolecular interaction strong enough to prevent breaking upon re-swelling.

Stretching- and drying-induced orientations of polysaccharide hydrogel are not new discoveries. Osorio-Madrazo et al. ${ }^{[19]}$ described drying-induced alignment of cellulose nanowhiskers in agarose hydrogels. Sehaqui et al. ${ }^{[20]}$ described the orientation of cellulose nanofibrils caused by stretching and drying of its wet film. None of the methods produced highly aligned hierarchical fibrous structures as in this work. A key difference between other drying methods and our method was that, we applied DCC in a physical hydrogel with diluted polymer concentration where the polymer chains were initially loosely cross-linked through weak physical bonds. Upon drying via the DCC method, the relatively rigid polymer chains 


\section{WILEY-VCH}

aligned easily along the tensile stress direction through the redistribution of physical interactions to form an oriented superstructure.

To verify the generality of the DCC method, we applied this method to another physical hydrogel from cellulose. Unlike Ca-alginate gel, the physical cellulose (p-cellulose) gel was solely based on H-bonding, which is a major supramolecular interaction found in biological systems. ${ }^{[12]}$ In principle, H-bonding of a low density physical cellulose gel should be tunable by the DCC method to create a superstructure similar to that of the alginate system. SEM images indicated that ND-cellulose gel had no ordered microstructure (Figure 4(a-i, ii)). The DCC-cellulose gel contained highly aligned microfibers consisting of multi-scale subunits of submicro- and nanofibrils (Figure 4(b-i, ii)), similar to those of the DCC-alginate gel. The results justified the applicability of the DCC method to different systems. Similar to the alginate system, the diameter of the microfibers decreased with increasing pre-stretching strain from 0\% to 50\% and 100\% (Figure 4(b-d)). Nanofibrils in Figure 4(d) are much extended than those in Figure 4(b), indicating a higher degree of alignment in 100\%DCCcellulose than that in DCC-cellulose. The mechanical properties of the gels were strongly dependent on the degree of pre-stretching during DCC (Figure 4(e)). The strength (Young's modulus and fracture stress) of the DCC-cellulose gels progressively increased with increase in pre-stretching strain (Table 1). The extensibility (fracture strain) and toughness (work of extension) progressively decreased with increase in pre-stretching (Table 1). Consistent with the pre-stretching effect, the ND-cellulose that was dried in the free state without stretching showed lower strength but higher extensibility than the DCC samples. The p-cellulose gel was very soft in comparison to the samples that experienced drying treatment. Enhanced H-bond formation led to the increase in the strength with the increase in pre-stretching, which was similar to that observed in the alginate system. The decrease in the stretchability with the increase in pre-stretching was attributed to the increased extension of the conformation of 


\section{WILEY-VCH}

nanofibrils in the sample. The cellulose gels showed mechanical hysteresis and partial self-

recovery, as shown in Figure 4f, indicating that the H-bonds served as reversible sacrificial bonds to dissipate energy in these gels. The increase in orientation led to increases in modulus and hysteresis area and decrease in recoverability (Figure 4g).
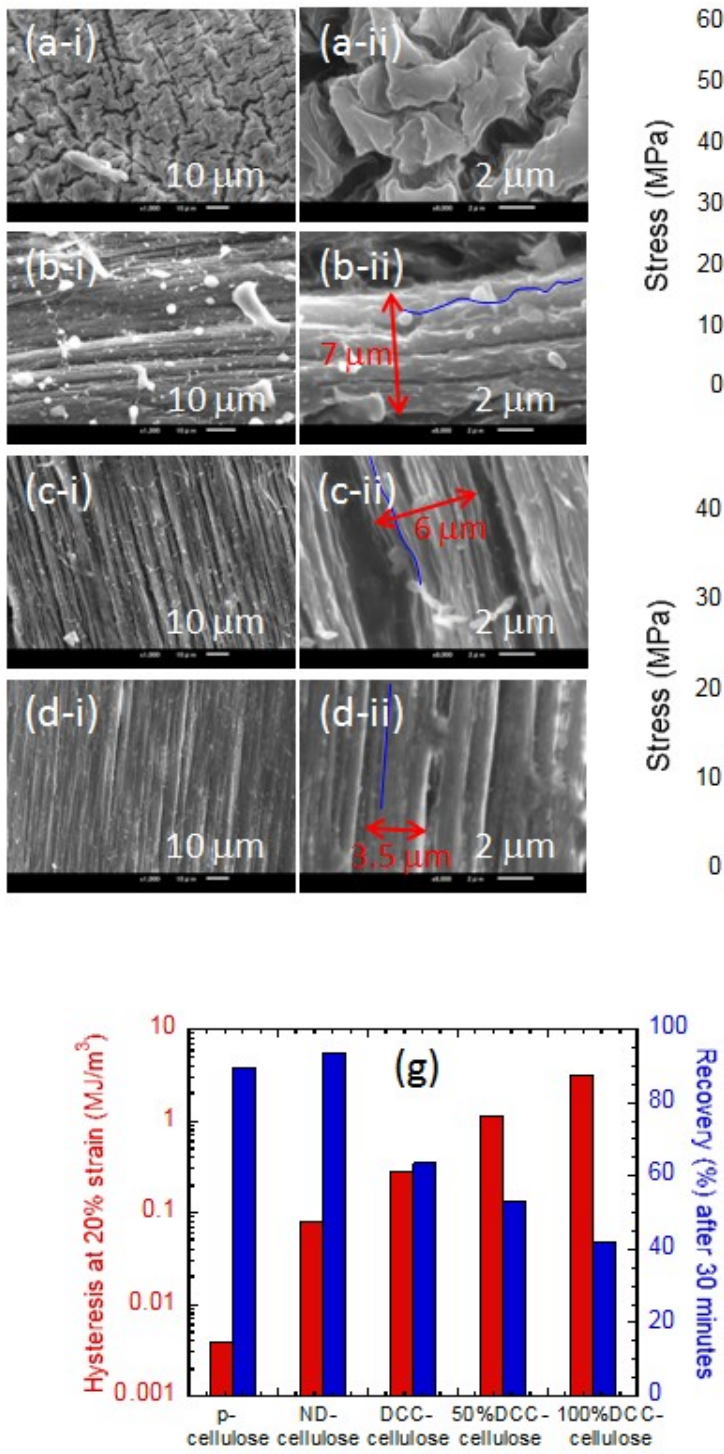
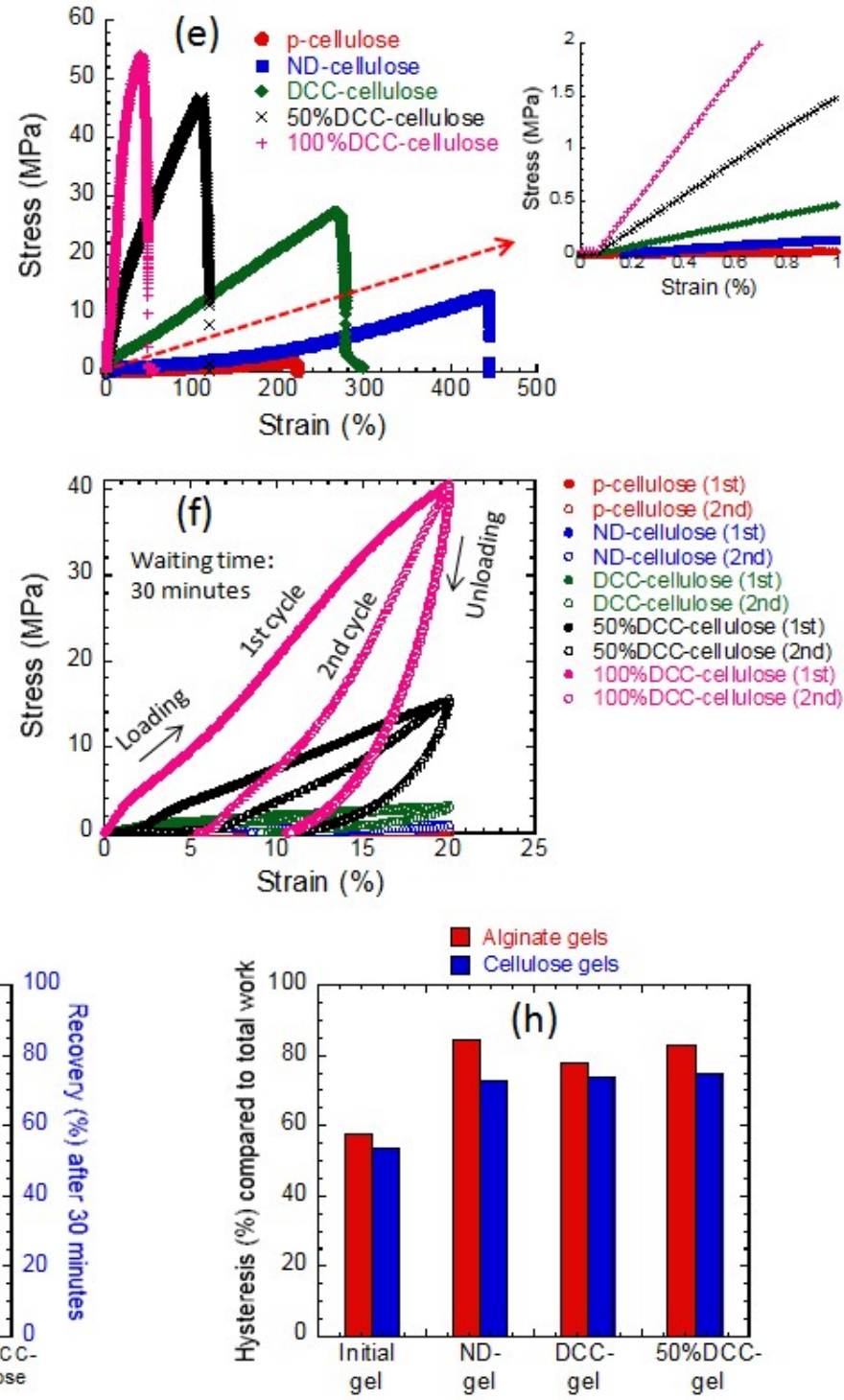

Figure 4. (a-d) SEM images of ND-cellulose gel (a-i, ii), DCC-cellulose gel (b-i, ii), $50 \%$ DCC-cellulose gel (c-i, ii), and 100\%DCC-cellulose gel (d-i, ii). The size of microfibers (measured by red arrow) decreased with increase in pre-stretching degree (b-ii, c-ii and d-ii). The blue lines in the images indicate the conformations of nanofibrils in the corresponding hydrogels. (e) Tensile stress-strain curves of different types of cellulose hydrogels. (f) Cyclic loading-unloading curves of cellulose hydrogels. The waiting time between the first and the second cycle was $30 \mathrm{~min}$. (g) Hysteresis area and recovery-estimated from the ratio of the second hysteresis area to the first hysteresis area. Tensile tests were performed at strain rate 


\section{WILEY-VCH}

$10 \mathrm{~mm} / \mathrm{min}$ in air at $25^{\circ} \mathrm{C}$. (h) Comparison of the hysteresis area (\%) of the first cycle (compared to the total work done by extension) for alginate and cellulose systems. The relative hysteresis area of cellulose gels was slightly lower than those of the corresponding alginate gels.

An interesting difference between cellulose and alginate systems was that fracture strain of the DCC-alginate gel increased relative to its non-oriented counterpart (ND-alginate) but prestretching led to less extensibility; while the fracture strain of the cellulose system decreased monotonously with stretching. This difference was attributed to the strength of the physical bonds. As revealed by studies on tough double network hydrogels ${ }^{[21-22]}$ and some other tough hydrogels, ${ }^{[16,23-24]}$ internal bond rupture during deformation caused an effect that delayed the fracture of materials by dissipating energy. The alginate system is based on both ionic and $\mathrm{H}-$ bonding. These bonds in alginate are less strong and can be ruptured by deformation, serving as reversible sacrificial bonds to toughen the hydrogel. Although the cellulose system was based only on H-bonding, the H-bonding in cellulose was very strong as seen in the poor solubility of cellulose fibers. As the degree of alignment increased, the H-bond of cellulose became too strong to rupture, leading to relative brittleness of the material. To confirm this argument, we compared the energy dissipation of the alginate system and the cellulose system by estimating the hysteresis area in relation to the total work for deformation. As shown in

Figure 4h, the alginate gel system systematically showed larger ratio of hysteresis area to total work, indicating the presence of more sacrificial bonds in the alginate system.

Maintaining a balance between structural and dynamic natures of sacrificial bonds was important to obtain both strength and toughness of the material. The mechanical properties of cellulose and alginate gels obtained by DCC were comparable with those of natural ligaments. ${ }^{[18]}$ This method offers an opportunity to tune the structural alignment and mechanical properties of a wide range of physical hydrogels. 


\section{WILEY-VCH}

We assumed that the rigidity of alginate and cellulose played important roles in sensing mechanical signals effectively to form hierarchical superstructures. We applied the DCC method to a physical polyvinyl alcohol (PVA) gel that had flexible polymer chains to justify this assumption. PVA gel was solely based on H-bonding, as was the cellulose gel. The persistence length of PVA was shorter than that of cellulose. ${ }^{[25,26]}$ As observed from SEM images, no oriented structure was formed in 100\%DCC-PVA gel (Figure S3). The result indicated that the backbone rigidity of the polymer is an important criterion for the formation of a hierarchical superstructure. This explained why hierarchical structures in nature mainly consist of rigid biopolymers such as collagen and elastin.

To conclude, drying a highly swollen physical hydrogel comprising rigid/semi-rigid polymer in confined condition produced perfectly aligned fibrous hydrogel with biomimetic hierarchical structure. During the confined drying process, sufficiently high tensile stress was built to align the polymer chains and multi-scale fibrous structures (from nano- to submicroto microscale) were simultaneously formed in the bulk hydrogel via physical association. This bottom-up growth of superstructures occurred only in relatively rigid polymers, but not soft polymers. Interplay of strength and toughness of the material required proper bonding strength between polymer chains to maintain a stable fibrous architecture and reversibly dissipate energy by breaking and reforming bonds (sacrificial bonds). By controlling the drying process with or without pre-stretching, oriented hierarchical structure and internal supramolecular interactions could be tuned in a wide range, which influenced the strength and toughness of the material. This study provides a general strategy for designing hydrogels with highly ordered hierarchical structures, which may find bio-applications in future.

\section{Experimental Section}

Experimental details are provided in the Supporting Information. 


\section{WILEY-VCH}

\section{Supporting Information}

Supporting Information is available from the Wiley Online Library or from the author.

\section{Acknowledgements}

Md.T.I.M. and J.P.G. conceived the idea, designed the study and wrote the paper. Md.T.I.M. and Y.Z.G. performed the experiments. All the authors analyzed and discussed the results. This work was supported by a Grant-in-Aid for Scientific Research (S) (No.17H06144) from the Japan Society for the Promotion of Science (JSPS). Md.T.I.M. thanks MEXT, Japan for a scholarship during PhD study. The authors thank Dr. Yoshinori Katsuyama for preparing the clamping device for the DCC method.

Received: ((will be filled in by the editorial staff))

Revised: ((will be filled in by the editorial staff)) Published online: ((will be filled in by the editorial staff))

\section{References}

[1] N. Bhattarai, Z. Li, D. Edmondson, M. Zhang, Adv. Mater. 2006, 18, 1463-1467.

[2] S. K. Chae, E. Kang, A. Khademhosseini, S. H. Lee, Adv. Mater. 2013, 25, 3071-3078.

[3] E. Kang, Y. Y. Choi, S. K. Chae, J. H. Moon, J. Y. Chang, S. H. Lee, Adv. Mater. 2012, $24,4271-4277$.

[4] Y. Cheng, F. Zheng, J. Lu, L. Shang, Z. Xie, Y. Zhao, Y. Chen, Z. Gu, Adv. Mater. 2014, 26, 5184-5190.

[5] Q. Wu, N. Chen, L. Li, Q. Wang, J. Appl. Polym. Sci. 2012, 124, 421-428.

[6] K. Yamaura, R. Kamakura, J. Appl. Polym. Sci. 2000, 77, 2872-2876. 


\section{WILEY-VCH}

[7] J. S. Bach, F. Detrez, M. Cherkaoui, S. Cantournet, D. N. Ku, L. Corte, J. Biomech. 2013, 46, 1463-1470.

[8] J. S. Bach, M. Cherkaoui, L. Corte, S. Cantournet, D. N. Ku, J. Med. Dev. 2012, 6, 045004:1-9.

[9] Y. Wang, T. Azaïs, M. Robin, A. Vallée, C. Catania, P. Legriel, G. Pehau-Arnaudet, F. Babonneau, M. M. Giraud-Guille, N. Nassif, Nat. Mater. 2012, 11, 724-733.

[10] E. G. Canty, K. E. Kadler, J. Cell Sci. 2005, 118, 1341-1353.

[11] C. P. Heisenberg, Y. Bellaiche, Cell 2013, 153, 948-962.

[12] M. J. Webber, E. A. Appel, E. W. Meijer, R. Langer, Nat. Mater. 2016, 15, 13-26.

[13] R. Takahashi, Z. L. Wu, M. Arifuzzaman, T. Nonoyama, T. Nakajima, T. Kurokawa, J. P. Gong, Nat. Commun. 2014, 5, 4490.

[14] A. C. Neville, Biology of Fibrous Composites: Development Beyond the Cell Membrane (Cambridge Univ. Press, 1993).

[15] W. J. Chung, J. W. Oh, K. Kwak, B. Y. Lee, J. Meyer, E. Wang, A. Hexemer, S. W. Lee, Nature 2011, 478, 364-368.

[16] J. Y. Sun, X. Zhao, W. R. K. Illeperuma, O. Chaudhuri, K. H. Oh, D. J. Mooney, J. J. Vlassak, Z. Suo, Nature 2012, 489, 133-136.

[17] D. Amiel, E. Billings, Jr., W. H. Akenson, Ligament structure, chemistry, and physiology. In D. M. Daniel, W. H. Akeson, and J. J. O’Connor (editors), Knee Ligaments: Structure, Function, Injury and Repair, pages 77-91. Raven Press, New York, 1990.

[18] H. J. Jung, M. B. Fisher, S. L. Y. Woo, Sports Med. Arthrosc. Rehabil. Ther. Technol. 2009, 1, 1-17.

[19] A. Osorio-Madrazo, M. Eder, M. Rueggerberg, J. K. Pandey, M. J. Harrington, Y. Nishiyama, J. L. Putaux, C. Rochas, I. Burgert, Biomacromolecules 2012, 13, 850-856. 


\section{WILEY-VCH}

[20] H. Sehaqui, N. E. Mushi, S. Morimune, M. Salajkova, T. Nishino, L. A. Berglund, ACS Appl. Mater. Interfaces 2012, 4, 1043-1049.

[21] J. P. Gong, Y. Katsuyama, T. Kurokawa, Y. Osada, Adv. Mater. 2003, 15, 1155-1158.

[22] T. Nonoyama, S. Wada, R. Kiyama, N. Kitamura, Md. T. I. Mredha, X. Zhang, T. Kurokawa, T. Nakajima, Y. Takagi, K. Yasuda, J. P. Gong, Adv. Mater. 2016, 28, 67406745.

[23] M. A. Haque, G. Kamita, T. Kurokawa, K. Tsujii, J. P. Gong, Adv. Mater. 2010, 22, $5110-5114$

[24] T. L. Sun, T. Kurokawa, S. Kuroda, A. B. Ihsan, T. Akasaki, K. Sato, M. A. Haque, T. Nakajima, J. P. Gong, Nat. Mater. 2013, 12, 932-937.

[25] L. M. J. Kroon-Batenburg, P. H. Kruiskamp, J. F. G. Vliegenthart, J. Kroon, J. Phys. Chem. B 1997, 101, 8454-8459.

[26] H. Li, W. Zhang, W. Xu, X. Zhang, Macromolecules 2000, 33, 465-469. 


\section{WILEY-VCH}

Table of content entry

Anisotropic hydrogels with perfectly aligned hierarchical fibrous structures were fabricated by a simple method. Drying a physical hydrogel by confining its length direction generated one-dimensional tensile force that controlled polymeric alignment and supramolecular interactions. We realized a tunable structure and mechanical properties in different types of rigid polymeric hydrogels and the properties were comparable with those of natural ligaments.

\section{Keywords}

Anisotropy, hierarchy, fiber, drying in confined condition, hydrogel

Md. Tariful Islam Mredha ${ }^{1}$, Yun Zhou Guo ${ }^{2}$, Takayuki Nonoyama ${ }^{1,3}$, Tasuku Nakajima ${ }^{1,3}$, Takayuki Kurokawa ${ }^{1,3}$, and Jian Ping Gong ${ }^{1,3 *}$

\section{Title}

A Facile Method to Fabricate Anisotropic Hydrogels with Perfectly Aligned Hierarchical Fibrous Structures

\section{ToC figure}

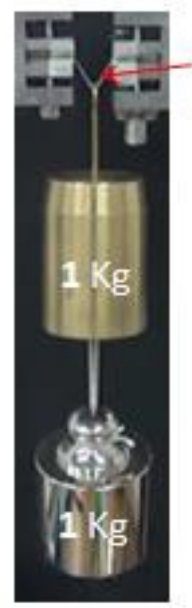

Gel

$(0.3 \mathrm{~mm} \times 3 \mathrm{~mm})$
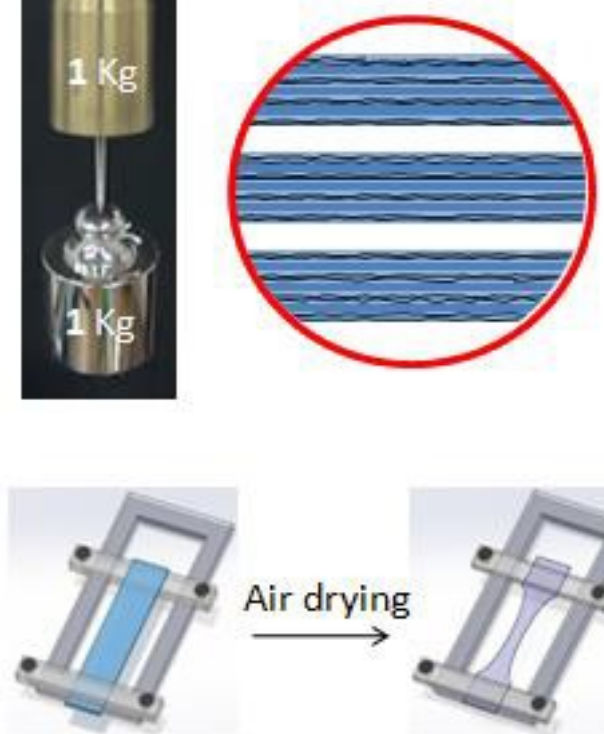
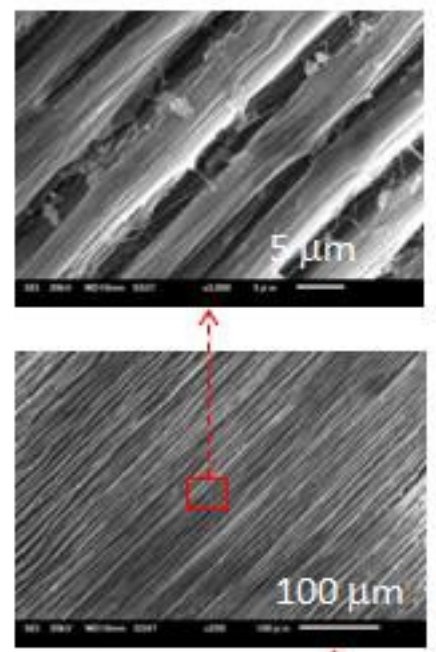

Swell in water 


\section{Supporting Information}

\section{A Facile Method to Fabricate Anisotropic Hydrogels with Perfectly Aligned Hierarchical Fibrous Structures}

Md. Tariful Islam Mredha ${ }^{1}$, Yun Zhou Guo ${ }^{2}$, Takayuki Nonoyama ${ }^{1,3}$, Tasuku Nakajima ${ }^{1,3}$, Takayuki Kurokawa ${ }^{1,3}$, and Jian Ping Gong ${ }^{1,3 *}$

\section{Materials and methods}

\section{Materials}

Analytical grade Na-alginate (viscosity 80-120 cP, Wako Pure Chemical Industries Ltd., Japan), cellulose (Advantec filter paper, Toyo Roshi Kaisha Ltd. Japan), polyvinyl alcohol (PVA) (Nacalai Tesque Inc., Japan), calcium chloride (Wako Pure Chemical Industries Ltd., Japan), N,N'-dimethylacetamide (TCI, Japan), lithium chloride (TCI, Japan), acetone (Kanto Chemical Co. Inc., Japan), and ethanol (Nihon Hamby Ltd., Japan) were used as received without further purification. All aqueous solutions were prepared using ultrapure deionized water.

\section{Preparation of alginate gels}

Alginate solution was prepared by dissolving $4 \mathrm{wt} \% \mathrm{Na}$-alginate in water and stirring overnight. To prepare Ca-alginate gel, reaction cell was first prepared by sandwiching two glass plates $(10 \mathrm{~mm} \times 10 \mathrm{~mm})$, separated using a $2 \mathrm{~mm}$ spacer. The upper end was kept open for solution insertion. Half of the reaction cell was filled with $4 \mathrm{wt} \% \mathrm{Na}$-alginate solution. 0.5 $\mathrm{M} \mathrm{CaCl}_{2}$ aq. solution was introduced from the upper empty part of reaction cell. $\mathrm{Ca}^{2+}$ ions diffused through the alginate solution. Ca-alginate gel started to form when alginate solution met $\mathrm{Ca}^{2+}$ ions. After complete gelation, Ca-alginate gel was taken out of the reaction cell and placed in $0.5 \mathrm{M} \mathrm{aq}$. $\mathrm{CaCl}_{2}$ solution for $1 \mathrm{~d}$ to complete the cross-linking process. Finally, the gel was thoroughly washed with water to remove non-cross-linked salt and polymer. The Ca- 


\section{WILEY-VCH}

alginate gel was used to prepare ND-alginate and DCC-alginate gels. ND-alginate gel was prepared by air drying and then re-swelling a piece of Ca-alginate gel. To apply DCC (drying in confined condition) on Ca-alginate gel, both ends of a sample of $\sim 1.5 \mathrm{~mm}$ thickness and 10 $\mathrm{mm}$ width were clamped using the device shown in Figure 1(I). The distance between the two clamps was $30 \mathrm{~mm}$. The gel was left in the atmosphere (temperature: $25^{\circ} \mathrm{C}$, humidity: $40-60 \%)$ to dry. After complete air drying, the gel was taken out of the device, the clamped part cut from both ends, and the dried sample placed in water to re-swell. This re-swollen gel was denoted DCC-alginate gel. To prepare $50 \% \mathrm{DCC}$-alginate, the gel was initially stretched to $50 \%$ and maintained in the pre-stretched condition for air drying. After complete drying, the gel was re-swollen in water.

\section{Preparation of cellulose gels}

Physical cellulose gel (p-cellulose) was prepared from filter paper as per a previously reported ${ }^{[1]}$ procedure with slight modification. Cut filter paper sheets were sequentially washed with water and ethanol. The paper was activated by $N, N^{\prime}$-dimethylacetamide (DMAc) for $12 \mathrm{~h}$ and then vacuum dried at $60^{\circ} \mathrm{C}$. To prepare cellulose solution, $0.75 \mathrm{~g}$ cellulose was dissolved in $100 \mathrm{~g} \mathrm{LiCl} / \mathrm{DMAc}(8 \mathrm{~g}: 92 \mathrm{~g})$. Cellulose solution was cast into a glass mold of 3 $\mathrm{mm}$ thickness. The solution was left in air under ambient conditions (temperature $25^{\circ} \mathrm{C}$, humidity 40-60\%). After $2 \mathrm{~d}$, the solution became gel. The gel was first solvated in ethanol with two changes. The gel was equilibrated in water for a few days, changing the water several times to obtain p-cellulose gel (thickness $\sim 1.5 \mathrm{~mm}$ ). ND-cellulose gel was prepared by drying and re-swelling a piece of p-cellulose gel in air. DCC-cellulose, $50 \%$ DCC-cellulose, and $100 \%$ DCC-cellulose gels were prepared by applying DCC to p-cellulose gel (thickness: $\sim 1.5 \mathrm{~mm}$, width: $10 \mathrm{~mm}$, length between two confined ends: $30 \mathrm{~mm}$ ) with initial elongations of $0 \%, 50 \%$, and $100 \%$, respectively. 


\section{WILEY-VCH}

\section{Preparation of PVA gels}

Physical PVA (p-PVA) hydrogel was prepared from PVA polymer according to a previously described procedure. ${ }^{[2]}$ PVA $(M w=2000$ and saponification value $>98 \%)$ solution $(10 \mathrm{wt} \%)$ was prepared in dimethyl sulfoxide/water (3:1, by weight) solvent by heating the solution at $90{ }^{\circ} \mathrm{C}$ for $2 \mathrm{~h}$. The solution was degassed in a vacuum oven and poured into a $2 \mathrm{~mm}$ thick glass mold. The glass mold was kept at low temperature $\left(4^{\circ} \mathrm{C}\right)$ for $12 \mathrm{~h}$. Finally, the frozen hydrogel was placed in deionized water for $7 \mathrm{~d}$ with continuous exchange of water to yield the p-PVA gel. The p-PVA gel was dried in air, annealed at $135^{\circ} \mathrm{C}$ for $4 \mathrm{~h}$, and re-swelled in water to obtain ND-PVA gel. To prepare 100\%DCC-PVA gel, a piece of p-PVA gel was dried in air under confined conditions (thickness: $\sim 1.5 \mathrm{~mm}$, width: $10 \mathrm{~mm}$, length between two confined ends: $30 \mathrm{~mm}$ ) with initial stretching of $100 \%$. The dried gel was annealed at $135{ }^{\circ} \mathrm{C}$ for $4 \mathrm{~h}$ and re-swelled in water.

\section{Structure}

The structures of the gels were characterized by polarizing optical microscopy (POM, Nikon, LV100POL) and scanning electron microscopy (SEM, JSM-6010LA, JEOL Ltd.). A color sensitized $530 \mathrm{~nm}$ tint plate was used for POM to distinguish polymer orientation. The orientation strengths of hydrogels were measured quantitatively from retardation values using a Berek compensator in POM. To prepare the sample for SEM observation, hydrated samples were freeze-dried using a freeze drying device (Advantage XL-70, VirTis freeze-dryer) and coated with gold using an ion-sputtering device (E-1010, Hitachi, Japan). The shapes and volumes of the samples were not changed after freeze drying.

\section{Water content}

The water contents of the gels were measured from the differences in weight of sample before and after freeze drying. 


\section{WILEY-VCH}

\section{Mechanical properties}

Tensile tests of all the alginate and cellulose hydrogels were conducted in air at room temperature $\left(25^{\circ} \mathrm{C}\right)$ using a commercial mechanical tester (Autograph AG-X, Shimadzu Co., Japan). Rectangular gels $\sim 10 \mathrm{~mm}$ in length were used. The tensile speed was $10 \mathrm{~mm} / \mathrm{min}$. Three samples were used for each tensile test. Cyclic loading-unloading test was carried out for alginate and cellulose gels up to $20 \%$ strain. The waiting time between cycles of each test was $30 \mathrm{~min}$. The gel was coated with silicone oil to prevent air drying during the waiting period between cycles. Stress was defined as the force divided by the initial area of the sample cross-section. The work of extension was calculated from the area under the stress-strain curve.

(a)

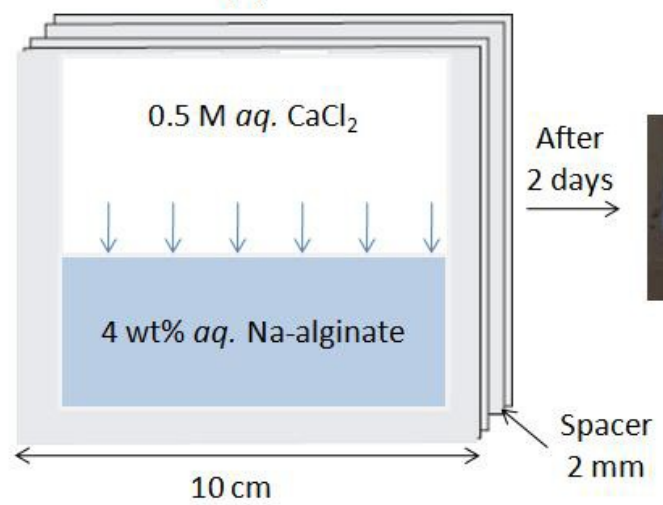

(b)

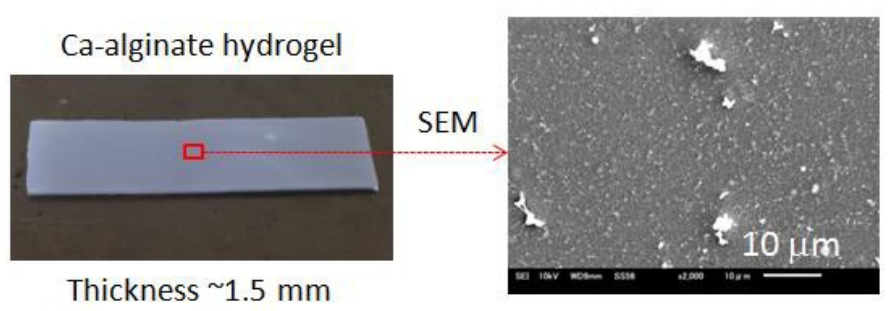

Water - 95 wt\%

Figure S1. (a) Preparation of Ca-alginate hydrogel by diffusion of $0.5 \mathrm{M} \mathrm{aq} . \mathrm{Ca}^{2+}$ ion through $4 \mathrm{wt} \%$ aq. Na-alginate solution. (b) Image of Ca-alginate hydrogel. (c) SEM image of Caalginate hydrogel. 


\section{WILEY-VCH}

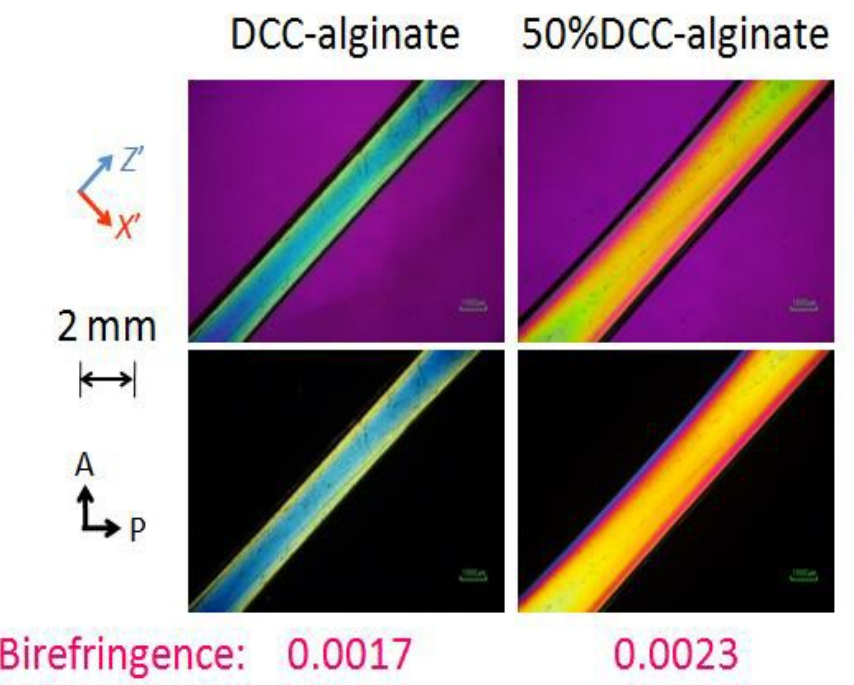

Figure S2. Polarizing optical microscopy (POM) images of DCC-alginate (1st column) and $50 \%$ DCC-alginate (2nd column) gels. Birefringence (3rd row) - calculated from the retardation value - indicates that polymers in 50\%DCC-alginate gel were aligned to a greater degree than those in DCC-alginate gel. All POM images are shown at the same scale. A: analyzer, P: polarizer. $X^{\prime}$ and $Z^{\prime}$ : fast and slow axes of the tint plate, respectively.

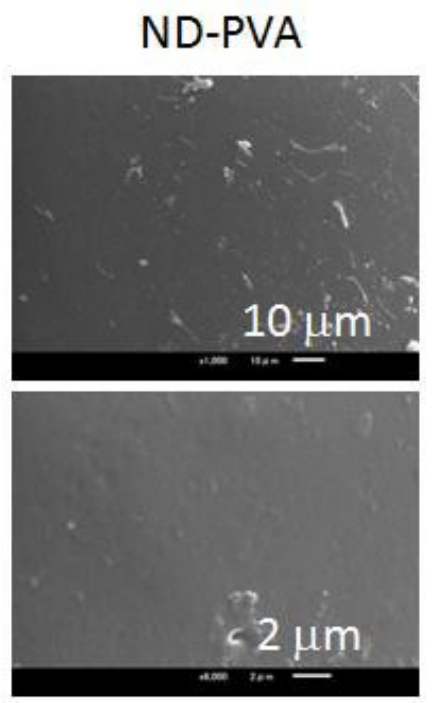

\section{0\%DCC-PVA}
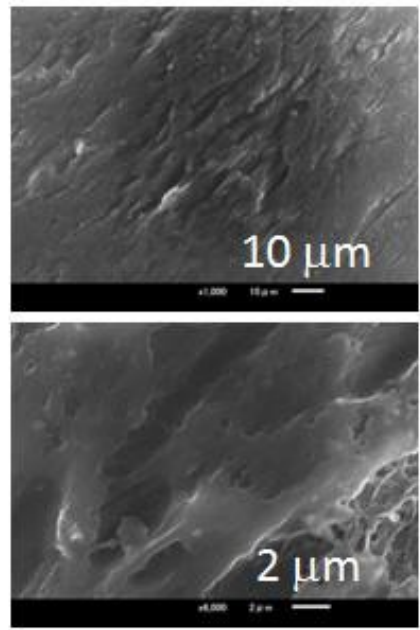

Figure S3. SEM images of ND-PVA gel and 100\%DCC-PVA gel. 


\section{WILEY-VCH}

Table S1. Dimensional changes in length, width, and thickness directions of Ca-alginate gel (water content $\sim 95 \mathrm{wt} \%$ ) after DCC along the central axis.

\begin{tabular}{lccc}
\hline Dimensions & Before drying & After drying & $\begin{array}{c}\text { Contraction ratio in DCC method } \\
\text { (ratio of final to initial dimension) }\end{array}$ \\
\hline Length & $30 \mathrm{~mm}$ & $30 \mathrm{~mm}$ & 1 \\
Width & $10 \mathrm{~mm}$ & $2.3 \mathrm{~mm}$ & 0.23 \\
Thickness & $1.5 \mathrm{~mm}$ & $0.26 \mathrm{~mm}$ & 0.17 \\
\hline
\end{tabular}

\section{References}

[1] W. Gindl, J. Keckes, Polymer 2005, 46, 10221.

[2] S. H. Hyon, W. I. Cha, Y. Ikada, Polym. Bull. 1989, 22, 119. 